\title{
SAFETY AND SECURITY OF HOSPITALS DURING NATURAL DISASTERS: CHALLENGES OF DISASTER MANAGERS
}

\author{
SEYED PAYAM SALAMATI NIA \& UDAYANGANI KULATUNGA \\ Centre for Disaster Resilience at university of Salford, Greater Manchester, United Kingdom.
}

\begin{abstract}
The purpose of this research is to explore some challenges that hospital disaster managers face in dealing with natural disaster events. In such events, it is crucial that hospitals remain safe and functional during and after the disaster; thus, hospitals at all levels need to plan for natural disasters and be aware of the requirement to remain in an operational condition both during and after any event. Evidence from around the world suggests that the malfunctioning of hospitals during a disaster have extensive impacts on both inbound and outbound patients; as such, disaster preparedness is a significant concern for hospital disaster managers. Hospital disaster management is important because of the critical services that healthcare facilities provide for injured people and existing patients. Therefore, developing a good management system for natural disaster events can help to ensure better efficiency and economy in the use of facilities and human resources within hospitals. Although appropriate disaster management can mitigate the impact of natural disasters in hospitals, there are some barriers that can prevent the effective management of these facilities in such events. For this study, secondary information was retrieved from the Internet and via academic database on sudden-onset natural disasters, and it was found that the: awareness, knowledge, disaster preparedness of hospital staff; allocation of building codes, and the relocation of buildings to higher levels, need be improved. Also, equipping health care facilities at the time of natural disaster events is important. To manage the challenges facing hospital disaster managers, a national strategy for the disaster management planning for hospitals is required.

Keywords: Challenges, disaster manager, hospitals, natural disasters
\end{abstract}

\section{INTRODUCTION}

The impact of a disaster can seriously disrupt or destroy the functioning of a community or a society, and involve widespread human, material, economic or environmental losses, which exceed the ability of the affected community or society to cope using its own resources [1]. Although often caused by nature, disasters can have human origins [2]; they can happen abruptly and be classified as dangerous and calamitous, which can thus overwhelm and disrupt essential infrastructures. From a different perspective, a disaster can also be described, for instance, on a household scale, where such an event can cause major sickness and social calamity, or an essential economic catastrophe. At the level of community impact, a disaster can manifest as a fire, flood, earthquake, the demolition of buildings, or as displacement through conflict. When it happens, particularly across a local district or city, a large number of the population can be affected [3]. Biswas and Choudhuri [4] define a natural disaster as the outcome when people are affected by natural hazards. In fact, they believe that, with a lack of proper emergency management, human vulnerability can be increased at such times, and that these events can also have an impact on the environment and on financial resources. Catastrophic and calamitous incidents that result from natural resources form a part of the natural disasters group, which includes tornadoes, eruptions, earthquakes, and floods [4]. Indeed, Shaluf [5] states that, due to their severity and unpredictability, natural disasters are often called, 'Acts of God'. As communities worldwide face an increasing frequency and variety of disaster, there is an urgent need to mitigate the risk from these events [6]. Therefore, in this context, 
disaster management is significant as it can reduce the negative impacts; such efforts aim to avoid or mitigate potential losses, appropriate assistance for the victims of a disaster, and deliver an effective and quick recovery. However, disaster management becomes even more important when considering the mitigation of risk in relation to natural disasters. Sabharwal and Swarup [7] define disaster management as, 'activities taken by the organisation in regarding unexpected incidents, which are adversely affecting people or resources and threatening the continued operation of the organization'. As such, the focus of most researchers in this field has been on the analysis of disaster management and relatively little attention has been paid to disaster prevention [8]. To better appreciate the significance of disaster management, it is important to understand the procedures required; Orlando, Danna, Giarratano, Prepas, and Johnson [9] state that the disaster management process includes four main phases, which are mitigation, preparedness, response, and recovery, and these should all be considered in an event. Indeed, disaster management processes may present several challenges that are overwhelming and complex, where additional actions in each step are required to mitigate the impact of the disaster [10]. Nevertheless, they argue that this four-stage process should be followed, and such an experience also used to assist in preparing for future events. Disaster management becomes even more critical for hospitals as the health sector has historically been particularly vulnerable to disaster. Health facilities at all levels deserve special attention in the case of natural disasters, as they are expected to continue patient treatment as well as care for those injured by the event [11]. For example, during the Bam earthquake (2003), almost all of the hospital buildings were damaged and there was chaos in relation to its operational capacities [12]. Furthermore, in order to continue providing a health service during the disaster, a large number of patients were relocated from the hospital to shelters during the earthquake, and some medicines and medical equipment also had to be moved [13]; this also caused severe disruption to the organisation. At any given time, hospitals have a population of patients, staff, visitors, and transient patients, but in a disaster event, the number may rapidly and substantially increase. The security and safety of all patients and occupants must be secured whilst staff continue to provide ongoing treatments and support services [14]. Hospitals are expected to be ready to play an essential role in reducing death and injury, and hospital readiness has been defined as the ability to effectively maintain hospital operations, sustain a medically safe environment, and adequately address the increased and potentially unexpected medical needs of the affected population [15]. Nevertheless, managing hospitals during a disaster presents particular challenges when there is a lack of proper disaster management planning before an event. Thus, this study focuses on the importance of hospitals in natural disaster events, and explores some challenges facing Iranian hospital disaster managers in natural disaster events. This paper is structured as follows: firstly, the concept of disaster, and the importance of disaster management in hospitals are reviewed. Secondly, some key challenges for hospital disaster management will be discussed, and finally, the paper provides a discussion that focuses on those challenges of disaster managers in hospitals, and identifies some improvement that can be considered in the light of some past disasters and their impacts on hospitals.

\section{LITERATURE REVIEW}

\subsection{Importance of hospitals in natural disaster events}

A hospital has been defined by PAHO [16] as a hotel, laboratory, office building and warehouse, and their importance is apparent in their function in providing critical services to patients at any time. In disaster events it is crucial that hospitals remain safe and functional 
during and after incidents. When facing disaster, health facilities at all levels deserve special attention, in that they must continue to provide patient treatment for those staying in their facilities whilst also treat persons injured by the event [17]. It is also important that their promotion and prevention programs are not suspended, such as prenatal care and haemodialysis, which places further strain on the organisation. Thus, to ensure the continuity of services in the face of natural disaster, a hospital must implement formal plans to deal with such eventualities. Furthermore, the construction plan of the building and its equipment must also remain in serviceable conditions. Many hospital authorities already recognise these requirements, which is why they have drawn up plans for dealing with disasters, and developed strategies to understand and mitigate these risk by using specially designed construction plans [18]. However, hospitals still need to incorporate prevention in such plans, in order to strengthen the impact of the committee's hospital disaster risk management system. Hence, it is crucial to formalise these considerations in the design and construction of buildings in order to provide security and better preserve certain critical areas of the hospital, such as the emergency department, intensive care units, diagnostic facilities, operating rooms, pharmacy, food and medicine stores, and services for registration and booking. Therefore, when planning a hospital, the architectural and structural designs should address safety specifications, not only in relation to aspects of the natural physical phenomena that can affect hospitals but also with regard to the social, economic and human needs [19]. Medical facilities are one of the most critical services in any region; however, the size and the priority of health equipment usage in a disaster event can be challenging to manage. The typical hospital depends on different factors, such as the: continuity of its utility supplies; sufficiency and availability of normal and skilled staff; accessibility and availability of medical and equipment supplies; and its accessibility for its daily operations. In fact, the failure of any of these factors can affect the continuity of medical services.

\subsection{Impact of natural disasters on hospitals}

Generally, hospitals are required to undertake special consideration in how they will manage the impact of a disaster. This is due to the need to continuously provide healthcare facilities for patients currently in the hospitals as well as deal with the unanticipated injuries of the people during the event. Hospitals and health facilities are the world's largest industry and such organisations (especially public hospitals) need a substantial bureaucratic structure to provide full services to patients [20]. According to World Health Organization [21] (also cited by Noralfishah, Thayaparan, Haidaliza, and Kulatunga [22] hospitals play critical roles in disaster events by providing communities with essential medical care. However, due to the nature of disasters the demand for health care services can rapidly and unexpectedly increase.

Thus, without sufficient planning, a disaster can overwhelm the functional capacity and safety of a hospital.

There are different impacts in disaster events, such as the ability of the hospital to function, the direct impact to patients and health equipment, and the physical damage to hospital buildings [23]. In disaster events, access to patient documentation and medicine can be affected and it is important to keep these in the safe. Also, supplying food and essential medicines, especially in the early hours of a disaster are crucial, and must be considered by disaster managers [24]. In terms of the time period, disasters can have different impacts on hospitals. The most typical impact was identified by the Disease Control Priorities Project [25], which noted a range of damage and loss, such as the loss of health equipment, a failure in the hospital's energy sources, a lack of staff, difficulty in accessing patients' documents (for example, 
the medical records), and issues in accessing the hospital buildings. For example, the earthquake that struck Mexico City in 1985 resulted in the collapse of 13 hospitals. In just three of the hospitals' buildings, 866 people died, 100 of whom were health personnel, and nearly 6000 hospital beds were lost across the city's metropolitan facilities. This illustrates the severity and extent of the challenges that can face hospital disaster managers when planning for such events. The 2003 Bam earthquake, with a magnitude of 6.7 on the Richter scale, destroyed the city of Bam in the South-East of Iran. The Bam earthquake is clasified as one of the major earthquakes in the 21st Century, when around 35,000 people were injured and more than 12,000 people had to evacuate their houses. This placed enormous, urgent demand on the disaster response agencies; however, the damage to health care infrustructures not a consideration at that time [13]. Table 1, provides an illustration of some of the damage sustained by health care infrastructures due to the Bam earthquake.

Further examples of the extent of the impact of natural disasters on hospital and health care facilities include; the earthquake that struck Mexico City in 1985, which resulted in the collapse of 13 hospitals. In just three of those buildings, 866 people died, 100 of whom were health personnel, and nearly 6000 hospital beds were lost across the metropolitan facilities. As a result of Hurricane Mitch in 1998, the water supply systems of 23 hospitals in Honduras were damaged or destroyed, and 123 health centres were affected. Peru reported that nearly $10 \%$ of the country's health facilities suffered damage as a result of the El Niño events in 1997 and 1998 [26]. Disasters can have two different impacts on hospitals in terms of the time period. According to the Disease Control Priorities Project's [26] report, some typical impacts can include damage and loss, which include: the loss of health equipment, a failure in the hospital's energy resources, a lack of staff, problems in

Table 1: Damage to health care infrastructures due to the Bam earthquake [13].

\begin{tabular}{lll}
\hline Health facility & Damage percentage\% & $\begin{array}{l}\text { Number of health } \\
\text { facilities }\end{array}$ \\
\hline $\begin{array}{l}\text { Dormitory of the facility of nursing } \\
\text { District health care management care }\end{array}$ & $100 \%$ & $\begin{array}{l}1500 \text { Sq.m } \\
1\end{array}$ \\
Facility of nursing and paramedics & $100 \%$ & 2000 Sq.m \\
Emergancy station (115) & $100 \%$ & 1 \\
Behvarz training centre & $100 \%$ & 1 \\
Emam district hospital (public) & $50 \%$ & 136 \\
Aflatoonyan hospital (private) & $100 \%$ & 65 \\
District health network expansion centre & $100 \%$ & 1 \\
Rural health centre (RHC) & $100 \%$ & 14 \\
Health posts (Urban) & $100 \%$ & 5 \\
Health house & $100 \%$ & 95 \\
Madiheh Maternity Hospital (public) & $40 \%$ & 54 beds \\
Urban health centre (UHC) & $100 \%$ & 10 \\
\hline
\end{tabular}


accessing patients' documents, and issues with access to buildings. In addition to this, patient documents and medicines can be affected and it is important to protect these. Also, supplying food and necessary medicine especially in the early hours of a disaster are crucial, which must be considered by disaster managers [24]. Therefore, it is important to manage hospitals appropriately so that they are able to better able to withstand the impacts of disasters. For instance, it is important to provide security and preserve certain critical areas of the hospital, such as the emergency department, intensive care units, diagnostic facilities, operating rooms, pharmacy, food and medicine stores, and services registration and booking. These all need to be a focus for hospital disaster management. The role, significance and specific needs of a hospital means that their design needs to carefully considered, arguably more so than for other more conventional buildings with less critical purposes, such as homes and offices [27]. Furthermore, during a disaster, it may become necessary to evacuate non-ambulant and ambulant patients; therefore, the response to disaster including evacuation procedures should also be well established and considered in a building design. These issues also demonstrate that proper disaster management is highly important for hospitals and health centres.

\subsection{Disaster management in Iranian hospitals}

Communities worldwide have been facing an increasing frequency and variety of disasters, and such incidents can have direct and indirect impacts, thus there is an urgent need to reduce disaster risk [28]. This is also linked with the development of resilient communities capable of recovering from disasters, which is of increasing concern in many countries [29]. For example, Iran is located in Central Eurasia, and in the Middle East; its population is about 75 million and as a country it is exposed to a wide range of man-made and natural hazards. According to EM-DAT, more than 180 disasters were recorded in Iran between 1900 and 2013, which were connected with 160,000 deaths and impacted 45,000 people. The most important natural hazards in this region are earthquakes, floods, and drought [23]. In Iran, the Emergency Management Centre (EMC) is under the control of the Deputy of Health, and the Centre's most important duties are the planning, supervision, and coordination in emergencies. Due to the potential impact of disasters on human life, health facilities have since been moved to the top of the agenda in terms of disaster management [32]. The 2003 Bam earthquake particularly influenced this, when the functions of the city's health system collapsed. Indeed, due to this impact, the event impact influenced a rapid reshaping of health provision in different regions; furthermore, training was provided and regional emergency operational services were planned at a different level to the district level. These steps aimed to ensure that health services were more resilient in the face of disaster, and thus able to respond appropriately.

The experience of the Bam earthquake also influenced the development of guidelines regarding disease surveillance in disasters, which have since been applied to subsequent disaster events [23]. Therefore, after the Bam earthquake, the progress of disaster risk management was significantly accelerated, and many improvements were made. Despite the valuable achievements and learning from the Bam earthquake and other disaster events, there is a room available for improvement in the disaster management systems in Iran, and in particularly in the Iranian health system. This challenge has changed in the last decade; since the disaster, the health system has been improved and upgraded, moving from the Centre for Environmental Health to the Emergency Management Centre, and now falls under the remit of the Deputy of Health Minister. Furthermore, the health system has since been successfully 
dealing with health-related problems, which range from the lowest to the highest level of the country's disaster management strategies. However, to secure better results it has been necessary to ensure effective collaboration between different sectors [33]. As briefly discussed, hospital disaster management in Iran is very important because of the critical services that such healthcare facilities provide in a country that has experienced a number disaster events. Not only do healthcare facilities need to continue to provide services to patients already undergoing treatment, but also to extend their services to those who are affected by a disaster. As such, disaster managers face additional and unpredictable challenges when managing hospitals in disaster events. In the sections 4 and 5, some challenges for hospital disaster managers will be reviewed.

\section{RESEARCH METHODOLOGY}

This research is based on secondary data analysis that defines and explains disaster impacts on hospitals, and reviews some challenges facing hospital disaster managers in the light of natural disaster events. The data have been gathered from peer reviewed journals, and some books and conference papers. Databases were used to gather information regarding: the context of disaster management in hospitals, the local pre-disaster availability of hospitals and health facilities, and the sudden impact of natural disasters on hospitals. For this phase of the study, a qualitative content analysis will form the major research instrument to analyses the secondary data. At this point, the primary data collection and analysis has not yet been completed, which will collect by interview relevant expert views regarding hospital disaster management. This current paper will thus purely adopt a qualitative data collection strategy, and consider a variety of secondary sources accessed through the Internet and academic databases.

\section{CHALLENGES FOR HOSPITAL DISASTER MANAGERS}

How hospitals respond to the demand for medical attention during and after a disaster event can be extremely challenging. Natural disasters impact on healthcare organisations, and remind disaster managers to pay attention to the safety of their staff, particularly their first responders and physicians [34]. Usually disaster managers in hospitals are faced with a range of challenges in such events, which include unexpected changes to newly injured or ongoing patient management, communication challenges, a lack of coordination, a lack of preparedness, and logistical deficiencies. For example, in August 2012, an earthquake occurred close to the cities of Ahar and Varzeghan in the East-Azerbaijan province in North-West Iran. This earthquake caused suffering for over 2 million people and forced many people sleep outside for two nights.

The earthquake killed 327 people, claimed more than 3000 injuries, and left more than 30,000 people homeless. Buildings in the stricken area experienced different levels of damage; however, most of the adobe buildings in the villages had collapsed and several masonry and framed buildings were damaged. Furthermore, some of the roads were damaged due to the surface faulting and geotechnical instabilities [35]. Although some of the bridges suffered damage, they remained serviceable after the event. Nevertheless, many of the essential facilities, such as hospitals, in the stricken areas were damaged and some industrial plants experienced economic losses due to the unsafe shutdown process after the earthquake. The performance of the hospitals was not acceptable in that they were not operable after the disaster event. One particular example of this was the Bagher-aloom Hospital in Ahar city, which suffered remarkable non-structural damages and was put out of commission after the earthquake. In particular, the collapse of the infill walls and of the false ceilings, and the overturning of medical equipment were major failures in the non-structural components of 

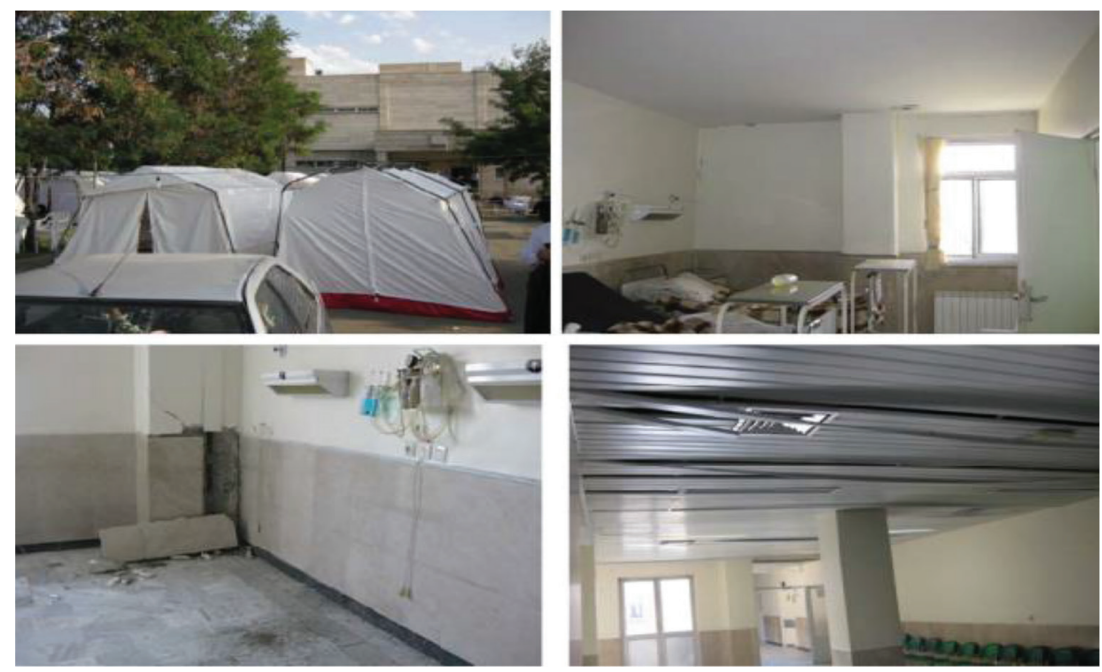

Figure 1: Herris Hospital and the Temporary Tents Outside Of Hospital Building [35].

the hospital. Due to such damage, treatment was carried out in temporary hospitals set up in tents, as it can be seen in Figure 1, and rescue teams had to transfer injured people to the hospitals in nearby cities. Heavy traffic jams in Tabriz-Varzaghan, Tabriz-Ahar and along other primary roads of the affected area caused significant trouble for the rescue teams, and the main reason for these was the large number of volunteers going to the affected areas to help the rescue teams. Thus, effective disaster planning could have mitigated some of the potential damage of this natural disaster, and provide a better health service during and after disaster to patients in the worst affected hospital. In the following sections, some specific challenges of disaster managers will be explained [35].

\subsection{Injured management}

The first issue for the majority of hospitals when facing a disaster can be in managing the numbers and requirements of injured people. Examples of this include the Herris hospital (in North-West Iran), which was destroyed in the 2012 earthquake, and the Ahar hospital, which saw its first and ground floors destroyed. Although both hospitals had to be evacuated, there were no special instructions prepared to deal with this eventuality. Although staff and patients had to be evacuated, some patients were able to move with their fellows left the health centres. However, later with rising tensions between patients and increasing damage to the structure of the hospital, it had been done slowly. After this earthquake, all affected patients were moved to Tabriz, and only one hospital was fully evacuated. In addition, the patients' documents also needed to be incorporated into the evacuation and eventual relocation. Therefore, it is not only the coordination of patients but also of their records that needs attention during and after a disaster, particularly when undertaking evacuations [36].

\subsection{Lack of communications management}

When a natural disaster occurs, some communication tools will be suspended, such as Wi-Fi signals, mobile and local telephone networks, and internet signals; for example, following the 
Herris and Ahar earthquakes local telephones failed, and there was also an issue with hospital phones in Tabriz. Furthermore, although the mobile signal was not cut off, the signal was weak in most of areas due to a failure in the centre and a spike in call traffic. Nevertheless, the issue was resolved after 1 day, which demonstrates a rapid response to the issue of communication access. [23].

\subsection{Lack of coordination}

A further challenge following the earthquake was the lack of proper coordination of relief, which can be classified into two categories: intra coordination, and inter sectoral coordination. In fact, a lack of coordination affects all activities, and this and the shortage of equipment are significant barriers to an effective service delivery, which in the case of the Bam earthquake impacted as follows: coordination problems with volunteers who came to assist; the lack of coordination among health centres, and among officials of different hospitals; the lack of a hospital incident command system and a failure to perform sufficiently frequent examinations of some of the injured; confusion between personnel and officials; the lack of coordination between prehospital emergency officials and hospitals; staff disregard of officials' orders; the intractable performance of tasks by staff; the absence of a command unity and unit commander fragmentation; unwarranted interventions of irrelevant people; the absence of official accountability; and disaster management interventions by county headquarters [36].

\subsection{Lack of preparedness}

The lack of preparedness of disaster managers can have a significant impact in providing an effective service to hospital patients in a natural disaster event. With a lack of previous staff training, a lack of initial planning to address issues arising from disaster events, no attention to previous experience, no anticipation of demands, a failure to meet demands, and no attention to the preparedness plans, the impact of natural disasters can be increased [24].

\subsection{Logistics deficiencies}

Other challenges facing disaster managers in such events can include logistic deficiencies, which can involve; a lack of funds for emergencies, challenges to security management, issues with donations management, inappropriate places to provide medical services, and difficulties with human resources management. Both hospitals in the North-West of Iran were destroyed after earthquake happened; however, they had only prepared one location in their hospital campuses to assign their health services, which were not adequate in for the numbers of personnel and injured people. For instance, there were inadequate sanitation facilities, and an issue with the cooling and heating systems [30]. Nevertheless, although other health centres were not damaged, they experienced the same problems. Furthermore, there were not a lot of donations in the hospital and no funding was predicted for such urgent moments, which also caused issues for the disaster recovery of the hospital and its continued operations. Although there were no security issues, people were rushing to get first aid treatment and medicines. Staff members complained about the temporary settlements in the hospital campuses in that there was fear about incoming injured people, and the security of the buildings, due to a lack of sustainability in the temporary constructions [31]. 


\section{DISCUSSION}

In this study, the concept of disasters, the importance of hospitals in such events, and the impact of natural disasters on hospitals were explored. In addition, some major challenges facing hospital disaster managers were extracted. The earthquake within the North-West region of Iran provided an example that illustrated the impact of previous disaster management failures and highlighted key areas of concern. As health facilities, such as hospitals, are fundamentally important in mitigating the risk of worsening health impacts from natural disaster events, they should be a priority for disaster management planning. The response to injured people should be planned within an appropriate location and in the minimum time possible. However, the physical damage to the hospital buildings and equipment following the earthquake had a direct impact on its service and ability to meet the urgent demands at the time [31]. According to the Ahar earthquake lack of preparedness was one of the major challenges in face of disaster managers because of lack of previous training of personnel and training programs, lack of prior planning for disaster situations.

Also failure to anticipate and meet demands. In addition lack of coordination was the other challenge, due to coordination issues with volunteers who were referred to help, lack of

Table 2: Summary of challenges in face of Disaster Managers [36].

\section{Lack of preparedness}

- No previous training of personnel and lack of training programs

- Lack of prior planning for disaster situations

- Failure to anticipate and meet needs

- Lack of attention to the experiences and lessons of previous disasters

Logistics challenges

- Inappropriate places for providing services to the injured

- Management of donations

- No emergency fund

- Security management

- Human resources management

Lack of coordination

- Coordination problems with volunteers who were referred to help

- Lack of coordination among hospital officials

- Lack of coordination among the authorities in different hospitals

- Lack of coordination among the prehospital emergency and hospital authorities

- No Incident Command System and not running if there was any

- Disobeying the orders of officials by personnel

- Intractable performance of tasks by staff

- Absence of command unity and single commander

- Frequent examinations of some injured

- Bewilderment of personnel and officials

- Fragmentation and repetition

- Inappropriate interventions of unrelated individuals 
coordination among hospital officials, lack of coordination among the authorities in different hospitals, lack of coordination among the prehospital emergency and hospital authorities, and failure incident command system made difficult situation for disaster managers at that event. In spite of lack of coordination and preparedness, there were other challenges such as logistic, and technical challenges because of failure management of donations, lack of emergency fund, issue with security management human resources management admission, and entry and exit management and discharging of injured people. Accordingly, accreditation organisations now require hospitals to have a preparation plan and demonstrate their preparedness for a disaster response. Thus, hospital preparation and identifying the need for disaster management is necessary in many countries that are susceptible to natural disasters. Nonetheless, the results of this research indicate that many health centres are often not ready for such eventualities [36].

Timely and effective responses to disasters require an organised disaster response system, which can provide the appropriate aid. Therefore, with all those challenges it is significantly important to prepare hospitals and get lessons with previous experience.

For instance providing disaster training for staff, equipping health care facilities in disaster events, and allocating building code can be productive solution to mitigate the risk of disasters in hospitals. In the following table, a summary of challenges is illustrated, taken from the existing cases that hospital disaster managers should be aware of.

\section{CONCLUSION}

In conclusion, preparing a hospital for a natural disaster event is important as it is likely to face high demand from injured people. Whether disasters are from flooding, hurricanes, severe heat waves, droughts, ice storms, tornadoes, typhoons, or fires are less significant than the need to respond quickly, appropriately, and with authority. The main issues are that firstly, there is no clear way to predict when a natural event will occur, and secondly that it will be difficult to determine about any potentially destructive trajectories. Nevertheless, it is important to prepare a hospital by maintaining its condition and learning from previous disaster events in order to mitigate the risk of hazards. In conclusion, it is crucial to have right disaster management plan in place to avoid and mitigate the risk of a disaster incapacitating a hospital. Hospital disaster managers have a critical role in keeping hospitals in a good condition as they provide the most strategic location in terms of relief in natural disaster events. Disaster managers may face a lack of coordination, and communication and logistics issues, which, as well as addressing at the time, should be considered as valuable learning for future disaster management plans. The next phase of the research will involve the collection and analysis of primary data from expert interviews with a view to capturing in depth knowledge on natural disasters and the challenges of hospital disaster managers.

\section{REFERENCES}

[1] UNISDR, UNISDR terminology for disaster risk reduction. United Nations International Strategy for Disaster Reduction (UNISDR) Geneva, Switzerland, 2009.

[2] Chen, J., Modern disaster theory: evaluating disaster law as a portfolio or legal rules. Emory International Law Review, 25, p. 1121, 2011.

[3] Vale, L.J. \& Campanella, T.J., The resilient city: How modern cities recover from disaster. Oxford University Press, 2005. 
[4] Biswas, B.C. \& Choudhuri, S.K., Digital information resources for disaster management of libraries and information centres. Bangladesh Journal of Library and Information Science, 2(1), pp. 12-21, 2012. https://doi.org/10.3329/bjlis.v2i1.12915

[5] Shaluf, I.M., Disaster types. Disaster Prevention and Management: An International Journal, 16(5), pp. 704-717, 2007. https://doi.org/10.1108/09653560710837019

[6] Lin Moe, T. \& Pathranarakul, P., An integrated approach to natural disaster management: public project management and its critical success factors. Disaster Prevention and Management: An International Journal, 15(3), pp. 396-413, 2006. https://doi.org/10.1108/09653560610669882

[7] Sabharwal, M. \& Swarup, A., The implementation of disaster management by Indian banks. International Journal on Arts, Management and Humanities, 1(1), pp. 73-80, 2012.

[8] Masellis, M., Thermal agent disaster and fire disaster: definition, damage, assessment and relief operations. In The management of mass burn casualties and fire disasters, M. Masellis \& S.W.A. Gunn (eds.). Springer, pp. 7-12, 2014.

[9] Orlando, S., Danna, D., Giarratano, G., Prepas, R. \& Johnson, C.B., Perinatal considerations in the hospital disaster management process. Journal of Obstetric, Gynecologic, \& Neonatal Nursing, 39(4), pp. 468-479, 2010. https://doi.org/10.1111/j.1552-6909.2010.01158.x

[10] WHO, Guidelines for drinking-water quality. World Health Organization, 216, pp. 303-304, 2011.

[11] Eybpoosh, M., Dikmen, I. \& Talat Birgonul, M., Identification of risk paths in international construction projects using structural equation modeling. Journal of Construction Engineering and Management, 137(12), pp. 1164-1175, 2011.

https://doi.org/10.1061/(asce)co.1943-7862.0000382

[12] Ardalan, A., Masoomi, GR., Goya, MM., Ghaffari, M., Miadfar, J., Sarvar, MR., Soroush, M., Maghsoodi, A., Holakouie Naieni, K., Kabir, MJ. \& Khankeh, HR., Disaster health management: Iran's progress and challenges. Iranian Journal of Public Health, 38(1), pp. 93-97, 2009.

[13] Djalali, A., Castren, M., Hosseinijenab, V., Khatib, M., Ohlen, G. \& Kurland, L., Hospital incident command system (HICS) performance in Iran; decision making during disasters. Scandinavian Journal of Trauma, Resuscitation and Emergency Medicine, 20(1), p. 14.

https://doi.org/10.1186/1757-7241-20-14

[14] Salamati Nia, S.P., Kulatunga, U. \& Thayaparan, M., The importance of disaster management and impact of it into hospitals. Paper presented at the SPARC 2016, Media city UK.

[15] Barbera, J.A., Yeatts, D.J. \& Macintyre, A.G., Challenge of hospital emergency preparedness: analysis and recommendations. Disaster Medicine and Public Health Preparedness, 3(S1), S74-S82, 2009.

https://doi.org/10.1097/dmp.0b013e31819f754c

[16] Ardalan, A., Masoomi, G.R., Goya, M.M., Ghaffari, M., Miadfar, J., Sarvar, M.R., Soroush, M., Maghsoodi, A., Holakouie Naieni, K., Kabir, M.J. \& Khankeh, H.R., Disaster health management: Iran's progress and challenges. Iranian Journal of Public Health, 38(1), pp. 93-97, 2009. 
[17] Eybpoosh, M., Dikmen, I. \& Talat Birgonul, M., Identification of risk paths in international construction projects using structural equation modeling. Journal of Construction Engineering and Management, 137(12), pp. 1164-1175, 2011.

https://doi.org/10.1061/(asce)co.1943-7862.0000382

[18] Kenny, C., Disaster risk reduction in developing countries: costs, benefits and institutions. Disasters, 36(4), pp. 559-588, 2012.

https://doi.org/10.1111/j.1467-7717.2012.01275.x

[19] Jaiswal, P. \& van Westen, C.J., Use of quantitative landslide hazard and risk information for local disaster risk reduction along a transportation corridor: a case study from Nilgiri district, India. Natural Hazards, 65(1), pp. 887-913, 2013.

https://doi.org/10.1007/s11069-012-0404-1

[20] Yarmohammadian, M.H., Atighechian, G., Haghshenas, A. \& Shams, L., Establishment of Hospital Emergency Incident Command System (HEICS) in Iranian hospitals: a necessity for better response to disasters. Iranian Red Crescent Medical Journal, 15(12), 2013. https://doi.org/10.5812/ircmj.3371

[21] World Health Orgainzation. Guidelines for drinking-water quality. World Health Organization, 216, pp. 303-304, 2011.

[22] Noralfishah, S., Thayaparan, M., Haidaliza, M. \& Kulatunga, U., Impact of flood disaster in Malaysia: a case study on public hospitals. Special Themed Session: Cities, Infrastructure and Cascading Natural Disasters, 28-33, 2015.

[23] Ardalan, A., Mowafi, H. \& Khoshsabeghe, H.Y., Impacts of natural hazards on primary health care facilities of Iran: a 10-year retrospective survey. PLOS Currents Disasters, 2013.

https://doi.org/10.1371/currents.dis.ccdbd870f5d1697e4edee5eda12c5ae6

[24] Nakhaei, M., Khankeh, H., Masoumi, G., Hosseini, M. \& ParsaYekta, Z., Health management in past disasters in Iran: a qualitative study. Health in Emergencies and Disasters, 1(2), pp. 107-115, 2015.

[25] Shaluf, I.M., Disaster types. Disaster Prevention and Management: An International Journal, 16(5), pp. 704-717.

https://doi.org/10.1108/09653560710837019

[26] Guha-Sapir, D., Hargitt, D. \& Hoyois, P., Thirty years of natural disasters 1974-2003: the numbers. Presses universityu de Louvain, 2004.

[27] McEntire, D. A. a., Disaster response and recovery: strategies and tactics for resilience (2nd ed.). John Wiley \& Sons, Hoboken, NJ, 2015.

[28] Lin Moe, T. \& Pathranarakul, P., An integrated approach to natural disaster management: public project management and its critical success factors. Disaster Prevention and Management: An International Journal, 15(3), pp. 396-413, 2006.

https://doi.org/10.1108/09653560610669882

[29] Rotimi, J.O., Wilkinson, S., Zuo, K. \& Myburgh, D., Legislation for effective postdisaster reconstruction. International Journal of Strategic Property Management, 13(2), pp. 143-152, 2009.

https://doi.org/10.3846/1648-715x.2009.13.143-152

[30] Boin, A. \& McConnell, A., Preparing for critical infrastructure breakdowns: the limits of crisis management and the need for resilience. Journal of Contingencies and Crisis Management, 15(1), pp. 50-59, 2007.

https://doi.org/10.1111/j.1468-5973.2007.00504.x 
[31] Alexander, D.E., Principles of emergency planning and management. Oxford University Press on Demand, 2002.

[32] DeRoeck, D., Bawazir, SA., Carrasco, P., Kaddar, M., Brooks, A., Fitzsimmons, J. \& Andrus, J., Regional group purchasing of vaccines: review of the Pan American Health Organization EPI revolving fund and the Gulf Cooperation Council group purchasing program. The International Journal of Health Planning and Management, 21(1), pp. 23-43, 2006.

https://doi.org/10.1002/hpm.822

[33] Babaie, J., Ardalan, A., Vatandoost, H., Goya, M. M., \& Akbarisari, A., Developing a performance assessment framework and indicators for communicable disease management in natural disasters. Prehospital and Disaster Medicine, 31, pp. 27-35, 2016. https://doi.org/10.1017/s1049023x15005452

[34] Francescutti, L.H., Sauve, M. \& Prasad, A.S., Natural disasters and healthcare: Lessons to be learned. In Healthcare Management Forum 2017 (Vol. 30, No. 1, pp. 53-55). Sage Publications, Los Angeles, CA, 2017.

[35] Razzaghi, M.S. \& Ghafory-Ashtiany, M., A preliminary reconnaissance report on August 11th, 2012, Varzaghan-Ahar twin earthquakes in NW of Iran. Report of International Association of Seismology and Physics of the Earth's Interior, 2012.

[36] Pouraghaei, M., Jannati, A., Moharamzadeh, P., Ghaffarzad, A., Far, M.H. \& Babaie, J., Challenges of hospital response to the twin earthquakes of August 21, 2012, in East Azerbaijan, Iran. Disaster Medicine and Public Health Preparedness, pp. 1-9, 2017. 